Working Paper Series

The Impact of Government Funded

Initiatives on Charity Revenues

Bradley Minaker

A. Abigail Payne

Working Paper No. 24/17

September 2017 


\title{
The Impact of Government Funded Initiatives on Charity Revenues*
}

\author{
Bradley Minaker ${ }^{\dagger}$ and A. Abigail Payne \\ $\dagger$ Department of Economics, McMaster University \\ $¥$ Melbourne Institute: Applied Economic \& Social Research, The University \\ of Melbourne; and Department of Economics, McMaster University
}

\author{
Melbourne Institute Working Paper No. 24/17 \\ September 2017
}

\begin{abstract}
* We would like to thank the Ontario Trillium Foundation for access to their data, to the PEDAL lab and staff for assistance in transforming and linking the data sets. We also thank participants of the CES-IFO Summer Institute Workshop on the Economics of Philanthropy for their comments as well as participants at presentations held at Canadian Institute for Advanced Research: Social Interactions, Identity, and Well-Being Study Group, Monash University, National Tax Association, and the International Institute for Public Finance. Support for this research has been funded through SSHRC insight and partnership development research grants. For correspondence, email<abigail.payne@unimelb.edu.au>.
\end{abstract}

Melbourne Institute: Applied Economic \& Social Research The University of Melbourne

Victoria 3010 Australia

Telephone +61383442100

Fax +61383442111

Email melb-inst@unimelb.edu.au

WWW Address melbourneinstitute.unimelb.edu.au 


\begin{abstract}
When a charity receives government funding does it undo the benefits of that funding by changing its behavior for the collection of revenues from other sources? Do donors change their behavior? In recent years, the classic question of understanding crowd out from the charity perspective has been studied by numerous authors. This paper explores the extent to which a government funded program for new charity initiatives crowds out revenue from other sources. We explore $11,000+$ applications by more than 4,500 charities for funding over a 10 -year period. We demonstrate that the revenues of the charity increase approximately $16 \%$ and that the effect of the grant extends several years. The results suggest a change in charity behavior that potentially may dampen the full effect and/or persistence of the government funding.
\end{abstract}

\title{
JEL classification: $\mathrm{H} 4$
}

Keywords: Charitable giving, crowd out 


\section{Introduction}

When a charity receives government funding do total revenues increase? Does the charity undo the benefits of the funding by changing its behavior in seeking revenues from other sources (such as fundraising) or do donors change their behavior? Granting agencies may be concerned that the effect of their grant may be lessened if revenues from other sources decline and are displaced by funding provided by the grant (known as "crowd out"). Recent research has suggested that much of the grant is crowded out, but that this crowd out is not complete and that most of the crowd out is due to reduced fundraising by the charity (see Andreoni \& Payne (2003, 2011, 2013a) and Andreoni, Payne \& Smith (2014)). ${ }^{1}$ Can granting agencies change the structure of their granting program to ensure that their grants are not crowded out? It may be that certain types of grants, such as those that fund new initiatives as opposed to those that fund existing programs may lead to different levels of crowd out.

This paper studies the effects of receiving a grant from a provincially funded foundation on total revenues for the recipient charities operating in Ontario, Canada. We follow Andreoni et al. (2014), a study that examined the effects of a UK lottery grant program. Similar to the UK program, the funding from the Ontario foundation was to support community based initiatives that were mostly new programs (Ontario Trillium Foundation (2016b)). Initially, annual funding provided to the foundation was approximately $\$ 16$ million per year and the grant recipients were human and social service based organizations. The funding program was restructured in 1999 and the provincial funds allocated to the foundation were substantially increased ( $\sim \$ 100$ million per year of funding). Although the focus of the programs operated by the foundation continues to focus on the building and support of vibrant communities, the missions of the organizations eligible for

\footnotetext{
${ }^{1}$ For a review of past studies of crowd out see Andreoni (2006b) and Andreoni and Payne (2013b)
} 
funding were expanded to include community oriented groups such those in the arts and environmental conservation. We study the effects of the funding awards for the period 1999 to 2012. Our study covers those applications by single applicant registered charities because of our ability to match their applications with annual data that captures revenues and expenses from their Canada Revenue Agency (CRA) information return. By matching information from these two data sources, we can explore the short term and persistent effects of the foundation grant on charity revenues.

The effects of the foundation grants on charity revenues are strikingly similar to those found for Andreoni, et al (2014). We find that the grants increase total revenues by $16 \%$ in the first year of funding and there continues to be growth in total revenues in subsequent years. This growth is observed for all sizes of charities except those with average revenues that are greater than $\$ 500,000$.

How does this growth in revenues relate to the notion of crowd out? If we explore the effect of the grant on one year of funding then we would conclude that the grant crowds out other revenue. A one dollar increase attributable to the foundation grant only increases total revenues by approximately 33 cents for small and medium sized charities. Over a three year period, however, there is an increase in total revenues that remains less than $\$ 1$ for small charities ( $\sim 92$ cents) but gets closer to $\$ 1$ if we study the effect over a five year period $(\sim \$ 1.02)$, suggesting a neutral effect of the funding on small charity operations. For medium-sized charities, we do not observe any crowd out over a three year period (a $\$ 1$ increase in grants results in an $\$ 1.23$ increase in total revenues) and some crowd in in the effect over a five year period ( $\$ 1.72$ increase in total revenues). For larger charities, our estimates are small but imprecisely measured, suggesting that the foundation grant had relatively little impact on increasing revenues which we attribute to the fact that the size of the grants to these charities represent a low proportion of large charity total revenues. 
The paper proceeds as follows: section II describes the funding program and discusses the importance of studying specific granting programs to understand better issues around crowd out. Section III describes the data set and presents summary statistics. Section IV presents the analysis for the overall effect of the grant, tests for crowd in or crowd out, and section V compares our results to those of Andreoni, et al (2014) and concludes.

\section{Description of Program Under Study}

The granting foundation under study is one that was created by the provincial government as an arms-length organization in 1982 with the mission of distributing a portion of the proceeds collected from a provincially administered lottery to promote the development of vibrant communities (Ontario Trillium Foundation (2016b)). The budget for the foundation in the early years was small and the grants were distributed to organizations primarily focused on the delivery of human and social services. In 1999, the funding and the structure of organization of the foundation dramatically. The funding ceased to be tied to lottery proceeds and instead was allocated as part of the budget process, increasing to approximately $\$ 100$ million per year. In addition, the types of organizations eligible to receive funding were expanded to include those providing services in the areas of arts \& culture, the environment, and sports \& recreation. (Ontario Trillium Foundation (2016a)).

Applications for funding to the foundation typically are considered under one of two main programs: community grants and province-wide grants. Across the province, there are 16 catchments that may receive funding. The province-wide program is for initiatives with a broad geographic focus, usually defined as covering three or more catchment areas. Our focus is on the distribution of funds under the community grants program. This program funds initiatives with an intent of having a clear and measurable impact on the local community and accounts for nearly $85 \%$ of all applications. The community grants program 
targets new initiatives by charities and non-profit organizations ${ }^{2}$ engaged in community oriented activities tied to services in the arts \& culture, social \& human services, sports \& recreation, and the environment. The applications can be from a single organization or multiple organizations. This study focuses on single charity applicants to the community program, given the ability to link information on applications to detailed financial information retrieved from the organization's information return filed with the Canada Revenue Agency.

The community grant program is administered by local catchment grant review teams comprised of approximately 18 to 25 volunteers that have applied for a position on the team. ${ }^{3}$ Each member typically serves a renewable term that ranges from one to three years. The local review team is serviced by a foundation staff member who oversees the collection and evaluation of the applications. Once submitted, an application will be assigned to the relevant catchment area for evaluation. Until 2003, applications were accepted and evaluated on an ongoing basis. Between 2004 and 2005, the process switched to one where an application deadline was imposed and the evaluations of the proposals were structured around these deadlines. By 2005, the foundation had converted to a process whereby applications are evaluated three times per year. The submission deadlines are March 1, July 1, and November 1.

Applications are first screened for basic eligibility criteria. This screening filters out applications that are either not eligible for funding or whose project does not fit the priorities

\footnotetext{
${ }^{2}$ This can include community groups such as library boards and small municipal governments. The key difference between non-profits and charities is that charities must use their resources for charitable activities - this constraint does not exist for non-profits.

${ }^{3}$ Volunteers wishing to apply for their local grant review team submit an application through the Public Appointment Secretariat (PAS). The PAS maintains a list of candidates for each catchment area and as vacancies arise qualified candidates are considered for appointment to the grant review team (Ontario Trillium Foundation (2011)).
} 
of the grant program. ${ }^{4}$ Projects with a request of greater than $\$ 100,000$ are given a more thorough examination that may include onsite visits by foundation staff. The foundation staff compile the information from the applications and subsequent research and present a recommendation of either approval or rejection to the grant review team. The grant review team then meets to review the applications and to submit their recommendations. As the funding pot is fixed, the review team assists in deciding the ordering of applications, effectively affecting which applications are funded. These decisions are then finalized by the foundation's board of directors.

This granting program is interesting to study for a number of reasons. First, the granting program is very large. This provides a broad set of charities that are eligible to apply for a grant. Second, the granting foundation is well known and may result in a positive signal to donors about the quality of the charity - this may cause crowd in of other sources of revenue (Payne (2001), Vesterlund (2003), Andreoni and Payne (2003) and Andreoni (2006a)). Third, and perhaps most important, we are able to observe information about all charities that apply for the grant, including those who do not receive a grant. Similar to Andreoni et al. (2014), we observe information about charities before and after they apply and so can compare charities that are successful with charities that are unsuccessful.

These grants are for specific programs and are typically programs that extend or expand an organization's operations. Thus, unlike a grant that supports the organization's general operations, we should query whether the organizations' and/or donors' reactions to learning about the receipt of a grant would be the same as it might be for grants that support the general operations of the organization. Similar to Andreoni et al. (2014), the foundation funding program under study allows us to study a relatively homogeneous set of

\footnotetext{
${ }^{4}$ It is unusual for an application to be screened out for not meeting the criteria of the grant program since the types of programs funded is very broad.
} 
organizations as well as utilize an identification strategy that focuses on studying organizations that apply for the funding versus just any organization.

Over the period under study, the application process has changed a few times. The information collected through the process that is of interest to this study, however, has not changed. Common over the study period are requirements to describe a proposed project, to provide details on the level of funding requested, time needed to complete the project, and to indicate whether the grant would support operating and/or capital expenditures. In addition to providing information and funding requests for the proposed project, organizations are expected to submit key information about its finances, its staff (e.g. number of volunteers and paid staff), and the types of services provided by the organization. We are able to utilize relatively consistently measured information from the application form and match this information to data points provided from the organizations information return filed with the CRA.

Our identification strategy is one that compares revenues within a charity before and after receiving after controlling for time-invariant characteristics of the charity and then comparing this difference to differences in revenues in the same catchment area and period of charities that applied but did not receive the grant. The strategy also controls for observable factors that might explain why some charities are winners and others are losers. In other words, we are employing a difference in differences strategy and will test for the sensitivity of this strategy.

Given the nature of the granting program, we might expect that a successful (funded) charity will expand and grow because it received funding to expand or add a new service. It could also use the resources to expand in one direction while contracting in another direction - a crowd out scenario. An unsuccessful charity, on the other hand, can choose to continue to seek funding from other sources (including receiving funding from the same foundation in a 
future round) or choose to continue to operate without the proposed expansion and/or new service. If the unsuccessful charity is successful in acquiring funding from another source in the same period as the funding is provided to the funded charity, then our identification strategy of comparing the growth in revenues to the two charities will be muted, or biased towards zero. Unfortunately, we cannot observe the actions of the charities in terms of their grant applications to other foundations and organizations.

In contrast, if there are stark differences between charities that are funded and charities that are not funded that would explain the differences in the success on the application and might also be correlated to the effectiveness of the charities, then our results could overstate the effectiveness of the granting program. Our identification strategy helps to mitigate this concern. Moreover, a good proportion of our charities eventually receive funding from the foundation, suggesting the programs are fundable but are funded at different times. The differences in success rates could be attributable to budget constraints and/or preferences of the members adjudicating the proposals. $^{5}$

\section{Data and Summary Statistics}

As explained previously, we are studying the effects of the grants for the period post expansion of the funding program, post 1999 up to 2012. During this period, applications were considered under two programs: a province-wide program that funded projects covering more than two or more catchment areas and a community program that funded projects covering one catchment area. Figure 1 depicts the total amount funded for these programs. For most years, the bulk of the funding is allocated to projects under the community program.

\footnotetext{
${ }^{5}$ If we limit our control sample to those charities whose proposals are denied one or more times but end up with a grant of funding for one or more applications, our results are slightly larger than those reported in this paper.
} 
In most years, the level of funding awarded under the community based programs is approximately four times the amount awarded for province wide funding.

As our identification strategy relies on comparing charities operating in the same catchments, we focus our analysis on those grants awarded under the community program. This allows us to compare revenues of organizations located in similar areas while controlling for community characteristics that will help to explain differences in programs offered across communities as well as within communities over time.

Applications in the community program can be organized into three groups: those submitted by registered charities, those submitted by non-profits (but not registered charities), and those submitted by multiple organizations. The number of applications for each of these groupings are depicted in Figure 2. The dominant group of organizations are single applications for registered charities, representing in most years $60 \%$ of the applications. To be a registered charity, the organization must meet various regulatory requirements set forth by the Canada Revenue Agency (CRA) and submit an annual information return to CRA that reports its activities, revenues, and expenditures. Organizations with registered charity status are permitted to issue tax receipts for donations.

The second group of applications are from non-profits. While both non-profits and registered charities are required to undertake activities that are for the public benefit, nonprofits have less onerous regulatory requirements in terms of compliance with CRA regulations and in the submission of information. Non-profits may receive donations but they are not permitted to issue tax receipts to the donor. Over the sample period there has been an increase in the number of applications by this group of organizations. Our information on these organizations is limited to what is provided in the application to the funding agency. Thus, we cannot observe revenues and expenditures for these organizations. 
The third group of applications are from groups of organizations. Usually the lead organization is a registered charity or a non-profit but other types of organizations (e.g. local government groups) may also be participating in the application. The proportion of applications from this group has remained relatively constant over time. While we can observe the participating organizations on the group applications, we do not observe how the funding is distributed across the organizations.

For the remainder of this paper, our analysis will focus on the single applications by registered charities. In addition to matching information from the grant application to information from to the CRA information return data, we match in information on the characteristics of the neighbourhood in which the charity operates based on sociodemographic measures from the 1996, 2001, 2006, and 2011 censuses. To properly reflect the neighborhood in which the charities operate we use the forward sortation area (FSA), the first three characters of the postal code in which the charity operates, as our level of geography. The FSA represents approximately 8,000 households. The measures we use from the census includes the average household income, total population, measures to capture the age distribution, and the percent of the population who are immigrants. These measures help control for the environment in which the charity operates, both from the perspective of where potential funding sources may arise as well as with respect to the differential needs of the communities. ${ }^{6}$

Table 1 reports key information about the charities under study. We group the applications into three year intervals except for the last two years for ease of presentation. In the first two columns, we report the number of applications and the success rate of these applications. Overall, the number of applications has not varied dramatically over the sample

\footnotetext{
${ }^{6} \mathrm{~A}$ detailed memorandum explaining the linking process is available from the authors.
} 
period. The success rate of the applicants, however, has varied. In the earlier periods, nearly $80 \%$ of the applicants were successful. In the later periods, the success rate has fallen substantially, to below $50 \%$ in the last year of our study. In columns 3 and 4 , we report the total amount of funding requested and awarded for each period, respectively. There are far more projects pitched than can be funded by the foundation. Overall, the requests range from a few thousands of dollars to well over one million dollars. In columns 5 and 6 , we report the statistics for the median amounts that were requested and awarded, respectively. The median requested amount is $\$ 77,000$ and the median awarded amount is $\$ 55,000$. In any given year, the maximum amount awarded under the community program is less than $\$ 500,000$. Focusing on the successful applications, on average, the amount awarded is $65 \%$ of the amount requested.

Figure 3a depicts the distribution of applications by catchment area for the charities we study applying to the community program. We have ordered the areas based on the approximate total population for that area. The largest population is Toronto - and not too surprisingly this is the area with the greatest share of applications. As we move across the catchment areas, however, population size and number of applications are not as strongly correlated as one might expect. Figure $3 \mathrm{~b}$ depicts the share of awards granted in each region, which follows a similar pattern to the applications. For example, the populations of Hamilton, Waterloo/Guelph, and London range from 400,000 to 500,000. The share of the applications/awards from these cities range from 4 to $7 \%$. In contrast, the populations of Windsor, Kingston, and Oshawa in in the range of 100,000 to 200,000. Their shares of applications/awards also are similar to larger areas, ranging from 6 to $8 \%$.

Thus far we have treated the applications as independent. It is not uncommon, however, for a charity to apply for funding more than once and to observe more than one grant to a charity. Panel A of Table 2 reports the distribution of applications based on the 
number of applications by a charity. Approximately $50 \%$ of the 4,720 charities in our sample apply for funding only once during the sample period. Approximately $94 \%$ of the charities apply for funding 3 or fewer times. In columns 4 and 5 we report the share of the charities grouped by number of applications that are observed being awarded once (column 3) or more than once (column 4). While a few charities are successful in obtaining more than one award, nearly two-thirds of charities receive one or fewer awards. Panel B reports the distribution of the awards based on the number of years of funding. Most of the awards are for one year of funding with the majority of awards covering three or fewer years of funding.

Panel $\mathrm{C}$ of Table 2 further explores the number of awards per charity as well as the average number of months between the end of one award and the start of the next. Overall, approximately $26 \%$ of the charities never receive an award and $41 \%$ of the charities receive only one award. While there are a few outliers, most charities receive 3 or fewer awards over the 13 years of study. The granting program places an emphasis on supporting new initiatives and discourages applications that simply support day to day operational expenditures. Thus, for the most part, we should assume that charities receiving multiple awards are seeking funding for different programs versus continued support of an existing program. Given the average gap between the end of one award and the start of the next award is 31 months, the data support this notion that charities receiving multiple awards are being funded for different programs.

Table 3 provides more detailed information from the applications and financial information. Panel A reports the mean and standard deviations of funding request, funding awarded, total revenue, private giving and total government funding. Panel B reports the average and standard deviations of paid employees and volunteers. In columns 1 and 2 we report the summary statistics for all applicant charities, regardless of size. In columns 3 to 8 , we report the statistics based on the relative size of the charity. Size was determined by 
computing the mean total revenue excluding revenues from capital gains observed for the charity over the sample period. We define charity size based on reported total revenues as follows: A small charity reports $\$ 100,000$; a medium charity reports between $\$ 100,000$ and $\$ 500,000$; and a large charity greater than $\$ 500,000$.

Looking across all charities, the mean amount requested by successful applicants is similar $(\$ 115,800)$ to those that are rejected $(\$ 121,600)$. There is greater variance, however, for the rejected applicants. It also appears that successful applicants typically are larger, by almost $20 \%$. Across the three groups of charities, the patterns are similar in that the funding requested is uniformly lower for successful than for unsuccessful applicants and the successful applicants are slightly bigger than the unsuccessful applicants.

Panel B of Table 3 reports information from the applications from the charities about the number of volunteers and employees. Small charities have on average less than one fulltime employee and around one part-time employee. Medium charities have closer to two full time and three part-time employees, while large charities have around 17 full-time employees and 13 part-time employees. There are also differences in the number of volunteers, with charities that receive the funding having around $20 \%$ more volunteers than those charities that do not receive funding.

\section{Effects of Successful Grants}

\section{A. Effect of Success on Total Revenue}

Akin to the approach taken by Andreoni, et al (2014), we analyze the effect of the grant along two dimensions. First, we examine whether we observe differences in overall charity revenues when a charity is funded. This is the basic difference-in-differences specification allowing us to observe whether the total revenues increase as a result of receiving an award. We study these differences for a period (three or five years) as well as 
allowing for separate effects for each year. Second, we study the effect of the dollar value of the grant on total revenue.

Figure 4 (a to d) illustrates the basic effects of receiving a grant from the funding agency. The year of the application and/or the award would be observed on the information return is identified as year " $\mathrm{t}$ ". Year " $\mathrm{t}+1$ " represents the year after the decision and year " $\mathrm{t}$ 1 " represents the year prior to the decision. For all applications we use year "t-2" as the base year and then compute the year over year percentage change in revenues reported on the CRA information return. For each box, the line within the box represents the median, the edges of the box represent the $25^{\text {th }}$ and $75^{\text {th }}$ percentiles and the outer lines represent the minimum and maximums. For ease of display, however, we capped the minimum at $-50 \%$ and the maximum at $150 \%$.

Focusing first on the applications that were declined, extending two years beyond the decision, the median change in revenue remains at zero. Near $t+2$, however, the distribution of the changes in revenue widens substantially suggesting that some of the charities have done well despite having the application declined. Moving onto the applications that were successful, we observe growth in revenues in years $t$ and $t+1$, overall and at the median. The growth, however, starts to dissipate by year $\mathrm{t}+2$. This is not too surprising, however, given we are measuring the year over year growth versus the growth since year $t-2$. Thus, by year $\mathrm{t}+2$, while the revenue growth has dissipated, the charities have continued to experience higher annual revenues compared to the period before receiving the grant.

Figures $4 \mathrm{~b}$ to $4 \mathrm{~d}$ depicts the differences based on charity size. There are striking differences for the small charities (Figure 4b). Total revenues for unsuccessful charities are more likely to decline year over year whereas the successful charities are more likely to experience growth over time. Unsuccessful medium charities (Figure 4c) have relatively flat 
growth around the time of decision whereas the successful charities have revenue growth that gradually declines. Finally, both successful and unsuccessful large charities (Figure 4d) experience revenue growth with the successful charities experiencing slightly greater growth.

Overall, Figure 4 is suggestive that charities with successful applications experience revenue growth for several years following the award of the grant. Relying on these raw statistics, however, may be misleading as there likely are other factors that contribute to this growth. To control for these factors, we move to a regression framework. We first focus on the overall effect of receiving an award on total revenue and follow the empirical framework by estimating a difference-in-differences model:

$$
y_{i t c}=\alpha_{i}+\lambda_{t}+\gamma_{c j}+\beta \text { Post }_{i t c}+\delta \text { Award }_{i t c}+\theta \text { Controls }_{i t c}+\epsilon_{i t c}
$$

where $y_{i t c}$ is $\log$ total revenue for charity $\mathrm{i}$, in year $\mathrm{t}$ and catchment $\mathrm{c} ; \alpha_{i}$ and $\lambda_{t}$ are charity fixed effects and year dummy variables, respectively; $\gamma_{c t}$ is a dummy variable for the period of application $\mathrm{j}$ in catchment area c; post is an indicator variable for the period after application for all charities that apply (with the period measured as either three or five years post application), award is an indicator variable equal to one for the period following the award of a grant (again either three or five-year period). The vector of controls include neighbourhood characteristics (average household income, total population, the share of the population aged 0 to 19,55 to 64 and over 65 , and the share of the population who are immigrants). The charity fixed effect controls for time-invariant characteristics of the charity (e.g. location, mission, operational structure), assisting in the control of differences across the charities applying for funding. The year dummy variables control for macro level changes that would affect all charities similarly (e.g. economic growth or downturn). Because our revenue information on the charities is provided on an annual basis, we effectively are comparing all applications by charities located in the same catchment area within the same 
year. The estimation clusters the standard errors at the FSA level, using cluster-robust Huber-White standard errors.

$\beta$ measures the effect on total revenues the outcome for all charities that applied for funding and are located in the same catchment area and period after the application. ${ }^{7}$ This coefficient will help to control for factors that may affect all charities within that area (e.g. an economic, demographic, or weather event). Our main parameter of interest is $\delta$ which captures the effect of receiving an award on total revenues for the period post award (three or five years). As the value of the award is a dummy variable ( 0 if no award or 1 if awarded funding), if $\delta=0$ this would suggest there is complete crowd out of the grant. If, however, $\delta>0$, then there could be a partial crowd out or a crowd in effect of the grant.

In addition to equation (1), we estimate separate effects of receiving an award by year using equation 2:

$$
y_{i t}=\alpha_{i}+\lambda_{t}+\beta_{s} \sum_{s=0}^{2 \text { or } 4} \text { Post }_{i(t+s)}+\delta_{s} \sum_{s=0}^{2 \text { or } 4} \text { Award }_{i(t+s)}+\text { OControls }_{i t}+
$$

$\epsilon_{i t}$

Table 4 presents the results for equations (1) and (2). Columns (1) through (4) reports the results when we run the analysis on all charities, regardless of size. The first two columns report the results when we allow the effect to extend three years and the latter two columns report the results when we allow the effect to extend five years. Overall, the results are very similar to those reported in Table 3. Receiving an award increases total revenues, on average, between $14 \%$ and $16 \%$.

${ }^{7}$ There are a few 661 cases where a charity applies more than once for a grant with the foundation over a single year. A handful (115) receive more than one grant. For the purpose of the analysis we identify success based on there being at least one successful application during the year. For charities with more than one grant award in a given year we sum the amounts of the award. 
In Table 3 we observed large differences in the size of the grant relative to total revenues for charities of different sizes, so we might expect the grant to affect charities differently depending on their size. Columns 5, 7, and 9 of Table 4 reports the overall effect of the grant for small, medium and large charities, respectively, for the estimation of equation (1). Columns 6, 8, and 10 reports the results for equation (2). We find that the effect is strongest for small charities, with the grant raising total revenues by $22.5 \%$ over a five-year period. When we allow for separate effects by year, however, there are very strong effects in the first two years that quickly dissipate by years 4 and 5 . For medium-sized charities we observe a positive effect of the grant, with the total revenues rising $13.3 \%$ over the five-year period. This effect is smoothly distributed across the five years with a slower dissipation. The effect for large charities is essentially zero. These findings are consistent when what we observed in the raw summary statistics of Table 3.

\section{B. Crowd in or partial crowd out?}

The previous section presented evidence that the grant had a positive effect on total revenue for small and medium charities and was completely crowded-out for large charities. What it failed to capture, however, was whether the grant increases total revenue dollar-for-dollar or by some other amount. If the grant increases the charities revenues by less than dollar-fordollar then the granting foundation may be concerned that the full impact of their grant isn't being realized by the charities. If the grant causes total revenues to increase by more than the amount of the grant, then the granting foundation needs to take this into account when it makes funding decisions. To test for the level of crowd out or crowd in we use the actual dollar value of the grant in our analysis follows Andreoni et al (2014), using the following specification:

$$
O_{i t}=\alpha_{i}+\lambda_{t}+\beta_{s} \sum_{s=0}^{4} \text { Post }_{i(t+s)}+\delta_{s} \sum_{s=0}^{4} \text { Award }_{i(t+s)} x \text { Amount }_{i t}+\text { AControls }_{i t}+\epsilon_{i t}
$$


where everything is the same as in equation (2) except that Amount represents the total amount of the grant that the charity receives. The one exception is that the dependent variable is now measured in levels instead of logs. This allows us to test the level of crowd out observed over a five-year period. $\delta_{0}+\delta_{1}+\delta_{2}+\delta_{3}+\delta_{4}=0$ suggests the award has been completely crowded out, $0<\delta_{0}+\delta_{1}+\delta_{2}+\delta_{3}+\delta_{4}<1$ suggests partial crowd out, $\delta_{0}+$ $\delta_{1}+\delta_{2}+\delta_{3}+\delta_{4}=1$ suggests the grant has a neutral effect (raises total revenue dollar for dollar), and $\delta_{0}+\delta_{1}+\delta_{2}+\delta_{3}+\delta_{4}>1$ would suggest crowd in.

Table 5 presents the results for the effect of the grant over a five-year period, with the coefficients representing the effect of each dollar of the grant on total revenue. First focussing on all charities (column 1), in the first year of funding one dollar of grant money raises total revenue by 39 cents. The coefficient is not statistically different from zero. For years two through five, however, one dollar of grant increases total revenue. Over a three year period, the sum of the effect of each dollar of the grant is $\$ 2.86$ supporting an argument that of a crowd in effect of the grant. Over five years, each dollar from the grant raises total revenue by nearly $\$ 6$.

In columns (2) to (4), we report the results from estimations that provide separate estimates based on charity size (small, medium, large). The results for small charities are reported in column (2). Similar to what we observed in Table 4, the strongest and biggest effects are observed in the first three years of funding. Aggregated over three years, the overall effect is just less than $\$ 1$, at .919 and this coefficient is not statistically different from 1 , suggesting the grant is revenue neutral - the funding increased revenues by the amount of the award but did not result in an increase in revenue growth for the firm. Aggregated over five years, the overall effect equals $\$ 1$, again suggesting a neutral effect. 
Moving next to the results for medium sized charities (column (3)), we again observe a long-term effect of the grant on total revenues. Over a three year period we can reject a neutral effect at the $10 \%$ level. Over a five-year period, the effect is close to $\$ 1.72$ and is statistically different from $\$ 1$, suggesting a crowd in effect of the grant. Finally, we report the results for large charities in column (4). Interestingly, the effect in the first year of funding $(\mathrm{t}=0)$ is imprecisely measure and the effect in the second year of funding is only significant at a $10 \%$ level. We do not begin to observe significant effects until the third $(\mathrm{t}=2)$ and beyond years. Given the size of the awards are relatively small for large charities and the effects are lagged, we are not sure of what to make of these estimates. We suspect there is more going on for the large charities that we can explain in our analysis.

These results demonstrate a variation of effects based on size of charity, and likely, reflects the importance of the grant to the charity as well as the ability of the charity to continue to provide additional services beyond the end of the grant. There is some evidence of limited crowd out for grants to small charities over a three-year period but the grant appears to be revenue neutral over a five-year period. For medium and large charities, we see evidence of crowd in from other sources. The patterns for charity sizes coincide with the results reported in earlier tables and figures.

\section{Discussion and Conclusion}

Our study closely follows Andreoni et al. (2014). In this section we compare our results to their findings. Panel A of Table 6 presents the estimates of the overall effect of the grant from both studies (Table 4 of this paper and Table 6 of Andreoni et al. (2014)). Andreoni et al. (2014) finds the grant increase total revenue by $22.2 \%$. Our results suggest an increase of $14.1 \%$. The pattern is similar in both studies with the effect largest for small charities (Andreoni et al. (2014), 40.4\%, our study 22.5\%), slightly smaller for medium charities 
(Andreoni et al. (2014)18.4\%, our study 13.3\%) and even smaller and insignificant for large charities (Andreoni et al. (2014) 4.3\%, our study 4.3\%).

Panel B shows similar patterns when accounting for the size of the grant (Table 5 of our paper, Table 7 of Andreoni et al. (2014)). The effect of each dollar (or pound) of the grant is largest for small charities, and is also largest in the first three years after the grant, with smaller (and sometimes insignificant) values for the fourth and fifth year after the grant is awarded. Testing for crowd out or crowd in reveals very similar patterns in both papers. The five-year sum of the effect of the grant for small charities reveals nearly a dollar-fordollar (or pound-for-pound) increase in total revenue for small charities, while for medium charities show around a $\$ 1.54$ (£1.64 for Andreoni et al. (2014)) increase in total revenue for each dollar (pound) of grant over a five-year period.

Our study focuses on a provincially run grant program in a single province in Canada, while Andreoni et al. (2014) uses a national grant program in the UK. Despite the differences in both the scope of the grant program, and the country in which the grant program takes place, we find remarkably similar results. Both studies show that the grant increases total revenue for charities, with the grant being revenue neutral for small charities, and the grant crowding-in revenue from other sources for medium charities. In both countries the funding program was from a quasi-government source (lottery proceeds) and is perceived to be a highly respected source of funding. Both sources also promoted applications for new programs versus continuation or the coverage of day to day operational expenses. In isolation but further strengthened in combination, the results from both papers suggest that the structure of the granting program can affect the impact on overall revenue sources for charities. 


\section{References}

Andreoni, James, 2006a. "Leadership Giving in Charitable Fund-Raising," Journal of Public Economic Theory, 8(1), 1-22.

Andreoni, James, 2006b. "Philanthropy" Handbook of the economics of giving, altruism and reciprocity, 2, pp.1201-1269.

Andreoni, James \& Payne, A. Abigail \& Smith, Sarah, 2014. "Do grants to charities crowd out other income? Evidence from the UK," Journal of Public Economics, 114, 75-86.

Andreoni, James \& Payne, A. Abigail, 2003. "Do Government Grants to Private Charities Crowd Out Giving or Fund-raising?," American Economic Review, 93(3), 792-812.

Andreoni, James \& Payne, A. Abigail, 2013a. "Crowding Oot: The Effect of Government Grants on Donors, Fundraisers, and Foundations in Canada," Department of Economics Working Papers 2013-10.

Andreoni, James and Payne, A. Abigail, 2013b. "Charitable giving," Handbook of public economics, 5, pp.1-50.

Ontario Trillium Foundation, 2016a. "FAQS," http:/www.otf.ca/who-we-are/faqs, accessed: 2016-09-12.

Ontario Trillium Foundation, 2016b. "History," http://www.otf.ca/who-we-are/history, accessed: 2016-09-12.

Ontario Trillium Foundation, 2011. "How to Apply as a Volunteer," http://www.otf.ca/en/aboutUs/volunteer_apply.asp, accessed: 2016-09-12.

Payne, A. Abigail, 2001. "Measuring the Effect of Federal Research Funding on Private Donations at Research Universities: Is Federal Research Funding More than a Substitute for Private Donations?" International Tax and Public Finance, 8, 731-751

Vesterlund, Lise., 2003. "The informational value of sequential fundraising," Journal of Public Economics 87(3), 627-657. 


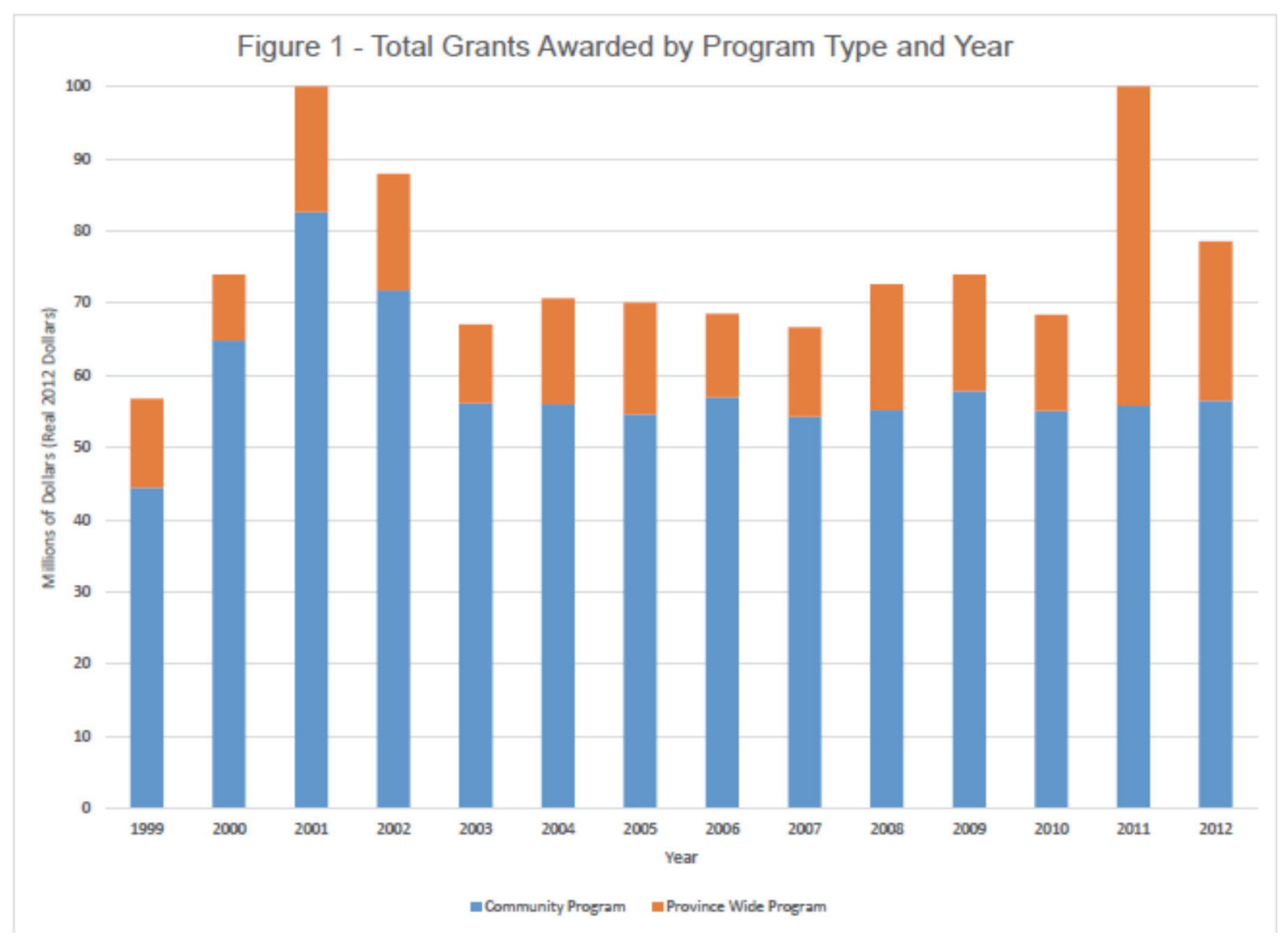


Figure 2 - Number of Applications by Type of Organization

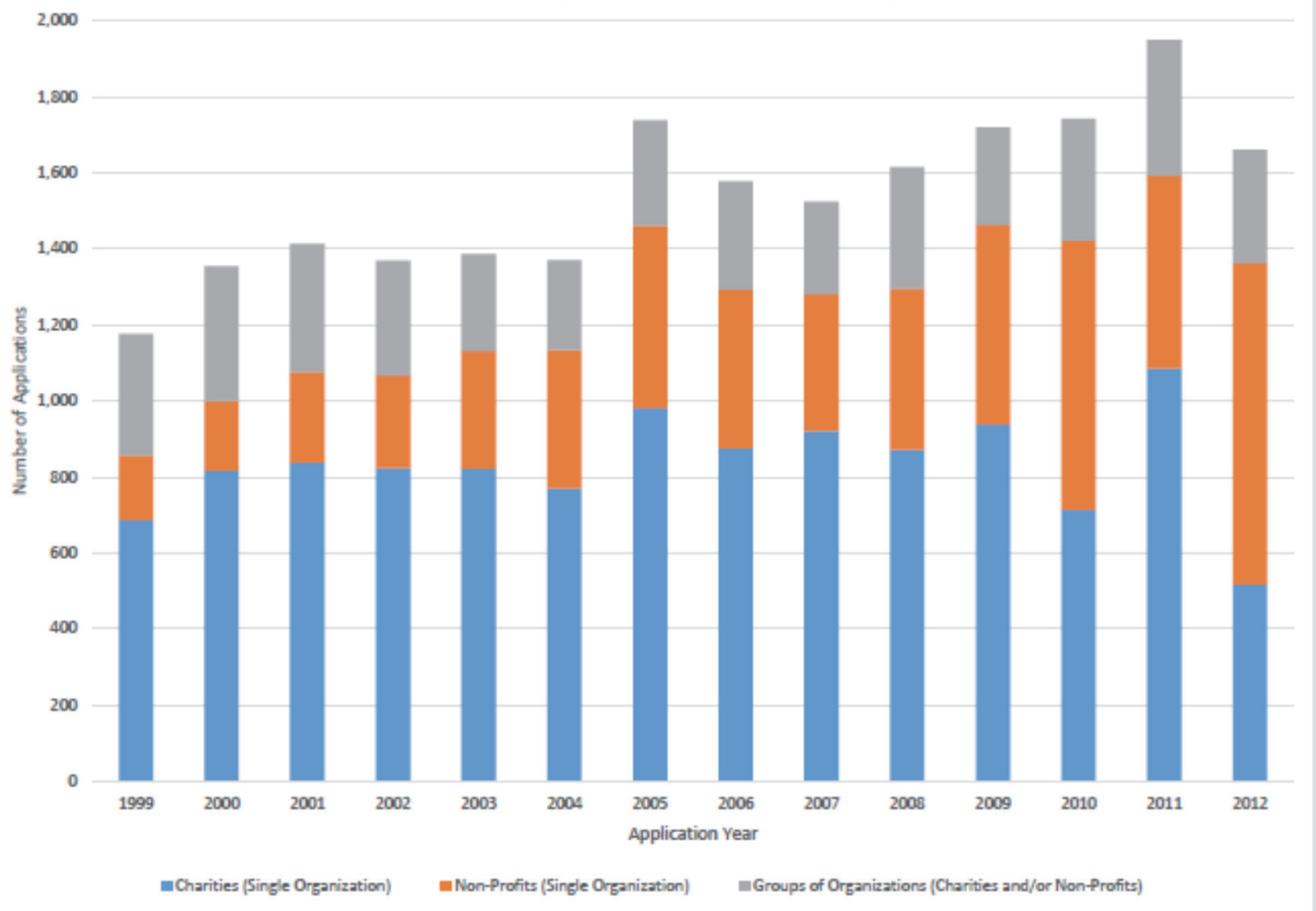


FIGURE 3A -

SHARE OF APPLICATIONS BY CHARITIES IN REGION, 1999-2012

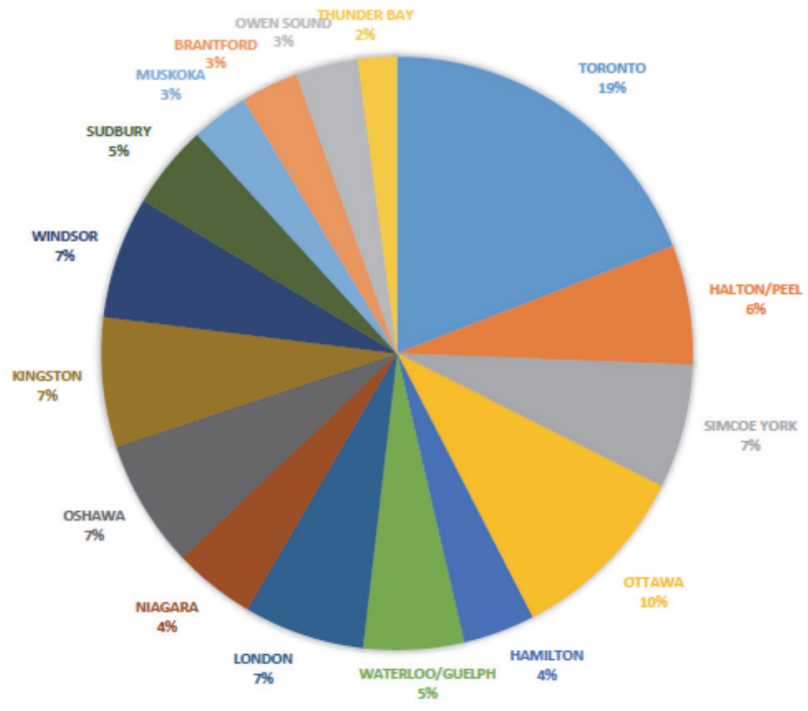

FIGURE 3B: SHARE OF AWARDS BY CHARITIES IN REGION, 1999-

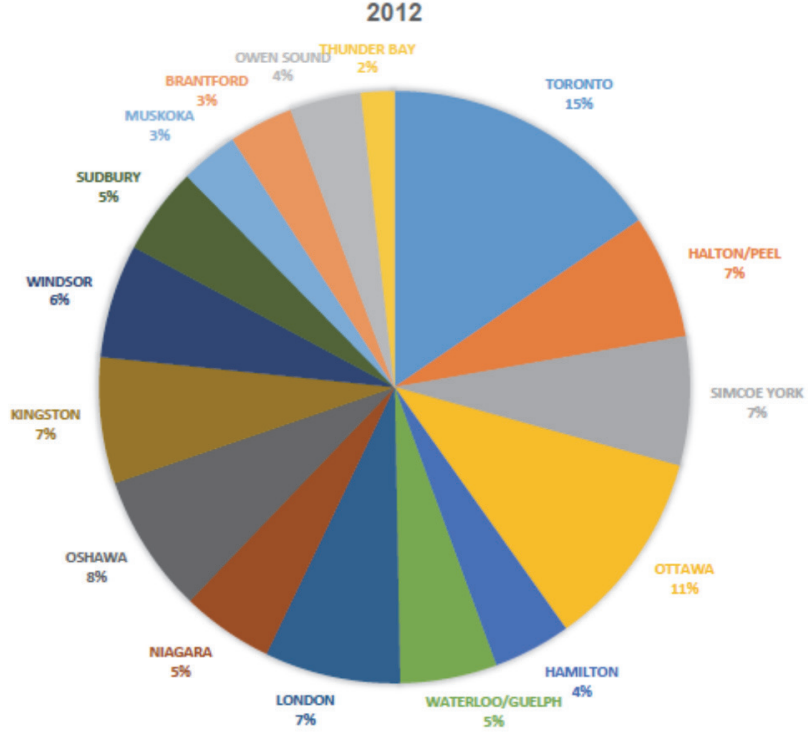


Figure 4a: Total Revenue Changes - All Charities

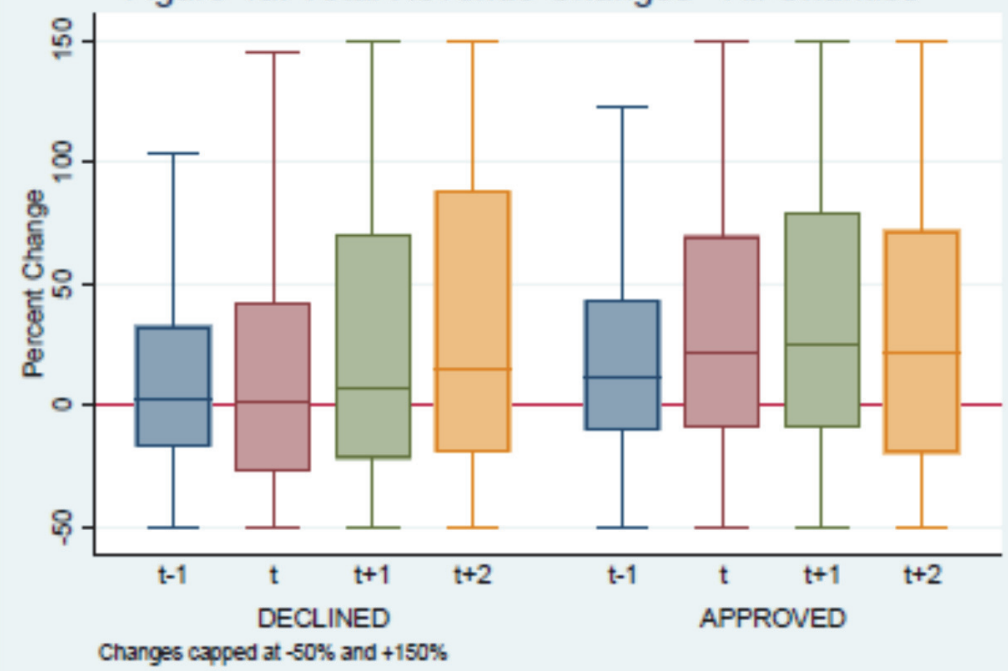

Figure 4b: Total Revenue Changes - Small Charities

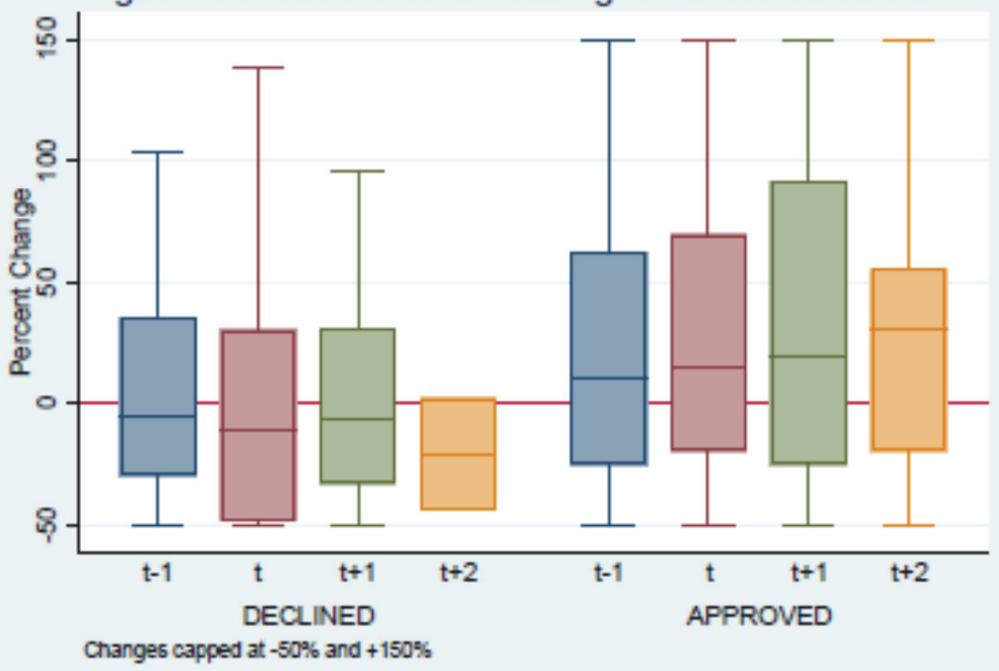


Figure 4c: Total Revenue Changes - Medium Charities

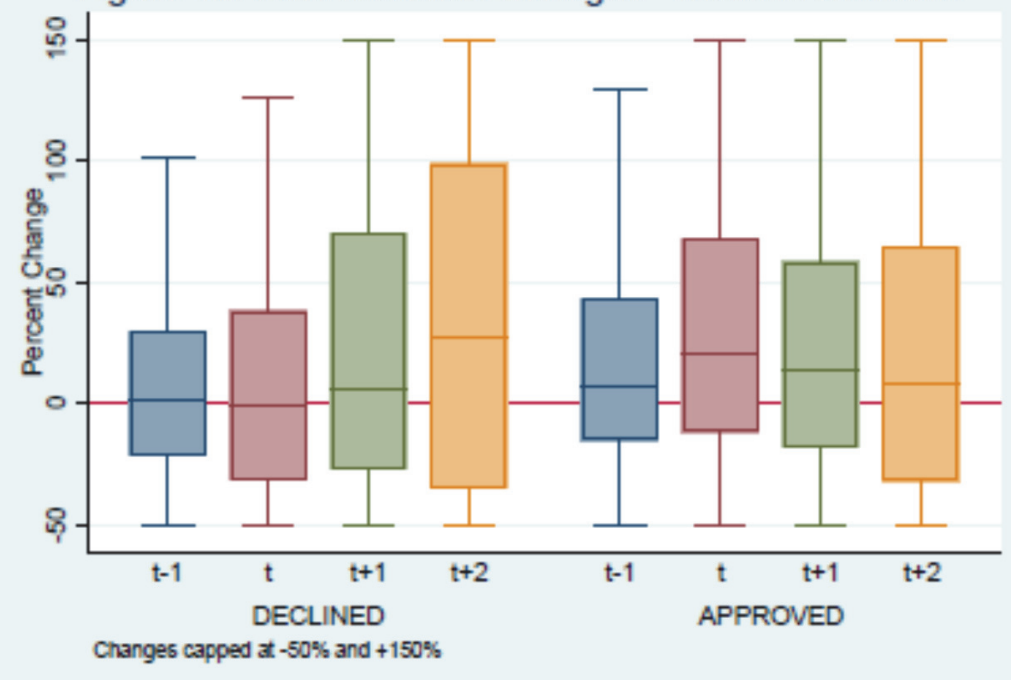

Figure 4d: Total Revenue Changes - Large Charities

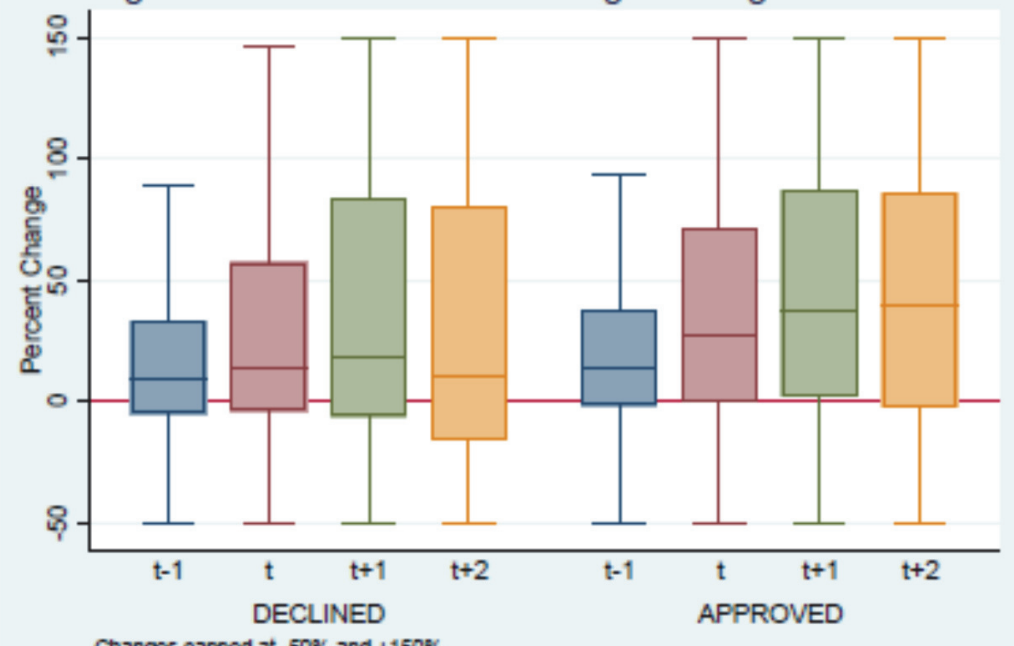

Changes capped at $-50 \%$ and $+150 \%$ 


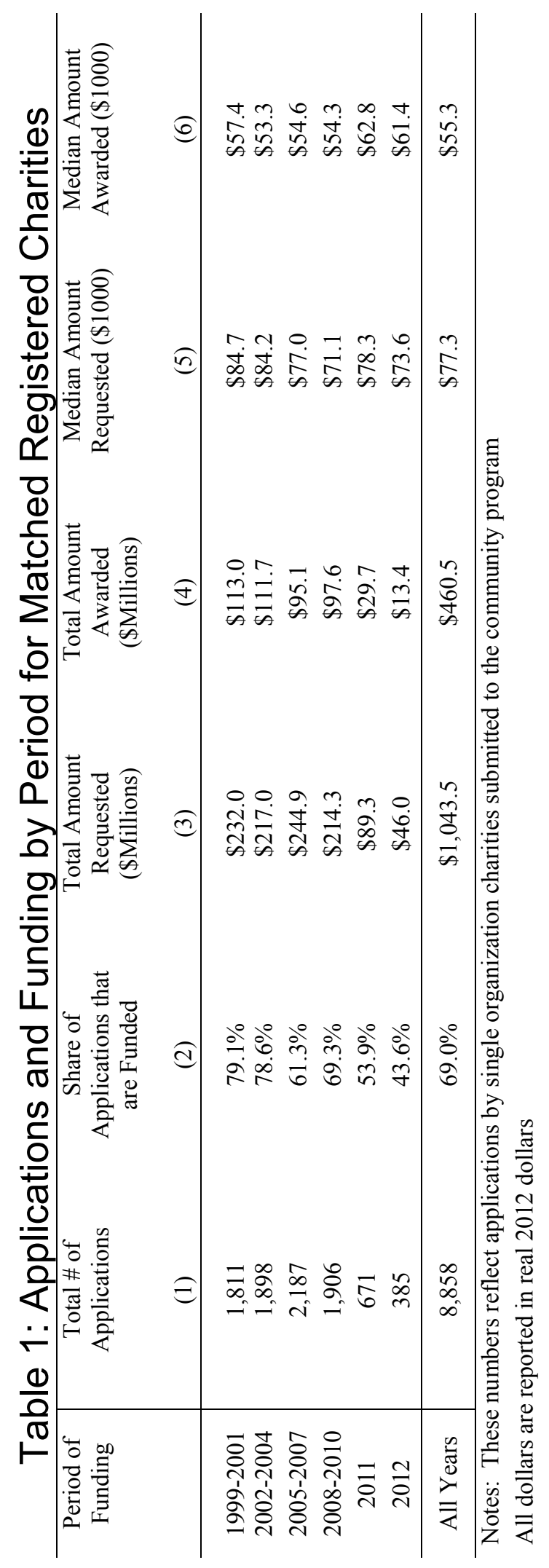




\section{Table 2: Number of Awards and Applications}

\begin{tabular}{|c|c|c|c|c|}
\hline \multicolumn{5}{|c|}{ Panel A: Distribution of Charities by Number of Applications } \\
\hline \# of Applications & $\begin{array}{c}\text { \# Charities } \\
\text { (1) }\end{array}$ & $\begin{array}{c}\% \text { of Charities } \\
\text { (2) }\end{array}$ & $\begin{array}{l}\% \text { of Charities that } \\
\text { receive at least } 1 \text { award } \\
\text { (3) }\end{array}$ & $\begin{array}{l}\% \text { of Charities that } \\
\text { receive } 2+\text { awards } \\
\text { (4) }\end{array}$ \\
\hline 1 Application & 2378 & $50.4 \%$ & $59.0 \%$ & \\
\hline 2 Applications & 1285 & $27.2 \%$ & $84.4 \%$ & $53.0 \%$ \\
\hline 3 Applications & 669 & $14.2 \%$ & $93.6 \%$ & $80.3 \%$ \\
\hline 4 Applications & 279 & $5.9 \%$ & $97.8 \%$ & $92.5 \%$ \\
\hline 5 Applications & 78 & $1.7 \%$ & $98.7 \%$ & $89.7 \%$ \\
\hline 6 Applications & 28 & $0.6 \%$ & $100.0 \%$ & $100.0 \%$ \\
\hline 7 Applications & 3 & $0.1 \%$ & $100.0 \%$ & $100.0 \%$ \\
\hline Total \# of Charities & 4720 & $100.0 \%$ & $74.2 \%$ & $33.7 \%$ \\
\hline \multicolumn{5}{|c|}{ Panel B: Length of Awards } \\
\hline $\begin{array}{c}\text { \# of Years Covered } \\
\text { by Grant }\end{array}$ & $\begin{array}{c}\text { \# Awards } \\
\text { (1) }\end{array}$ & $\begin{array}{c}\% \text { of Awards } \\
(2)\end{array}$ & & \\
\hline 1 & 3,456 & $57.8 \%$ & & \\
\hline 2 & 1,227 & $20.5 \%$ & & \\
\hline 3 & 1,123 & $18.8 \%$ & & \\
\hline 4 & 84 & $1.4 \%$ & & \\
\hline 5 & 86 & $1.4 \%$ & & \\
\hline Total \# of Awards & 5,976 & & & \\
\hline \multicolumn{5}{|c|}{ Panel C: Number of Awards and Time between Awards } \\
\hline \multirow{2}{*}{$\begin{array}{l}\text { \# of Grants Awarded } \\
\text { Per Charity } \\
\text { (conditional on } \\
\text { applying at least } \\
\text { once) }\end{array}$} & \# of Charities & $\begin{array}{l}\% \text { of Charities } \\
\text { in Sample }\end{array}$ & $\begin{array}{l}\text { Average \# of months } \\
\text { between end of first grant } \\
\text { and start of second grant }\end{array}$ & \\
\hline & $(1)$ & (2) & (3) & \\
\hline None & 1,224 & $25.9 \%$ & & \\
\hline 1 & 1919 & $40.7 \%$ & & \\
\hline 2 & 938 & $19.9 \%$ & 35.3 & \\
\hline 3 & 436 & $9.2 \%$ & 26.3 & \\
\hline 4 & 154 & $3.3 \%$ & 19.3 & \\
\hline 5 & 38 & $0.8 \%$ & 16.2 & \\
\hline 6 & 10 & $0.2 \%$ & 11.8 & \\
\hline 7 & 1 & $0.0 \%$ & 9.6 & \\
\hline
\end{tabular}

Notes: The number of months between the end of one award and start of another is calculated by the authors, using the decision dates for consecutive awards and the length of the grant. 


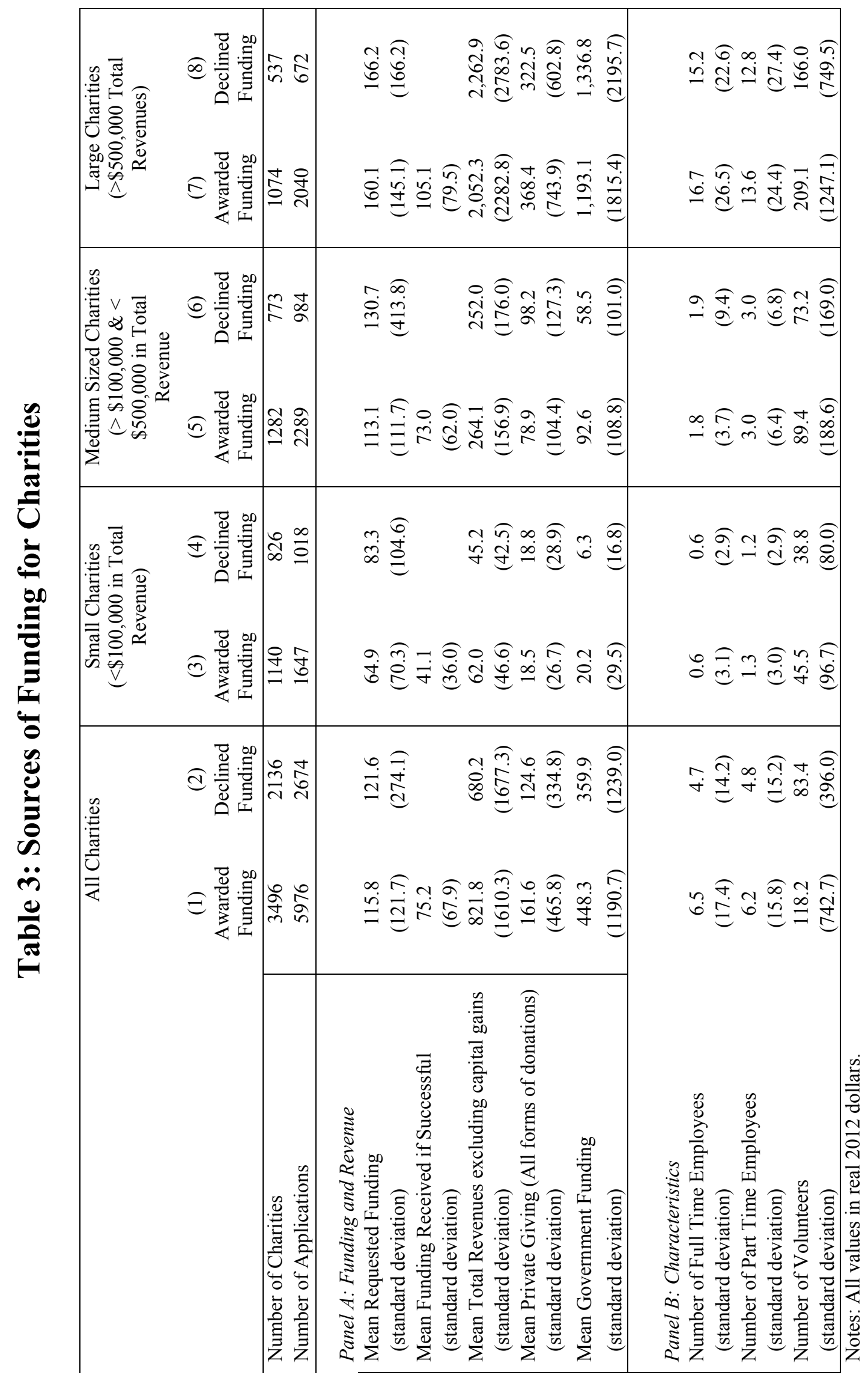




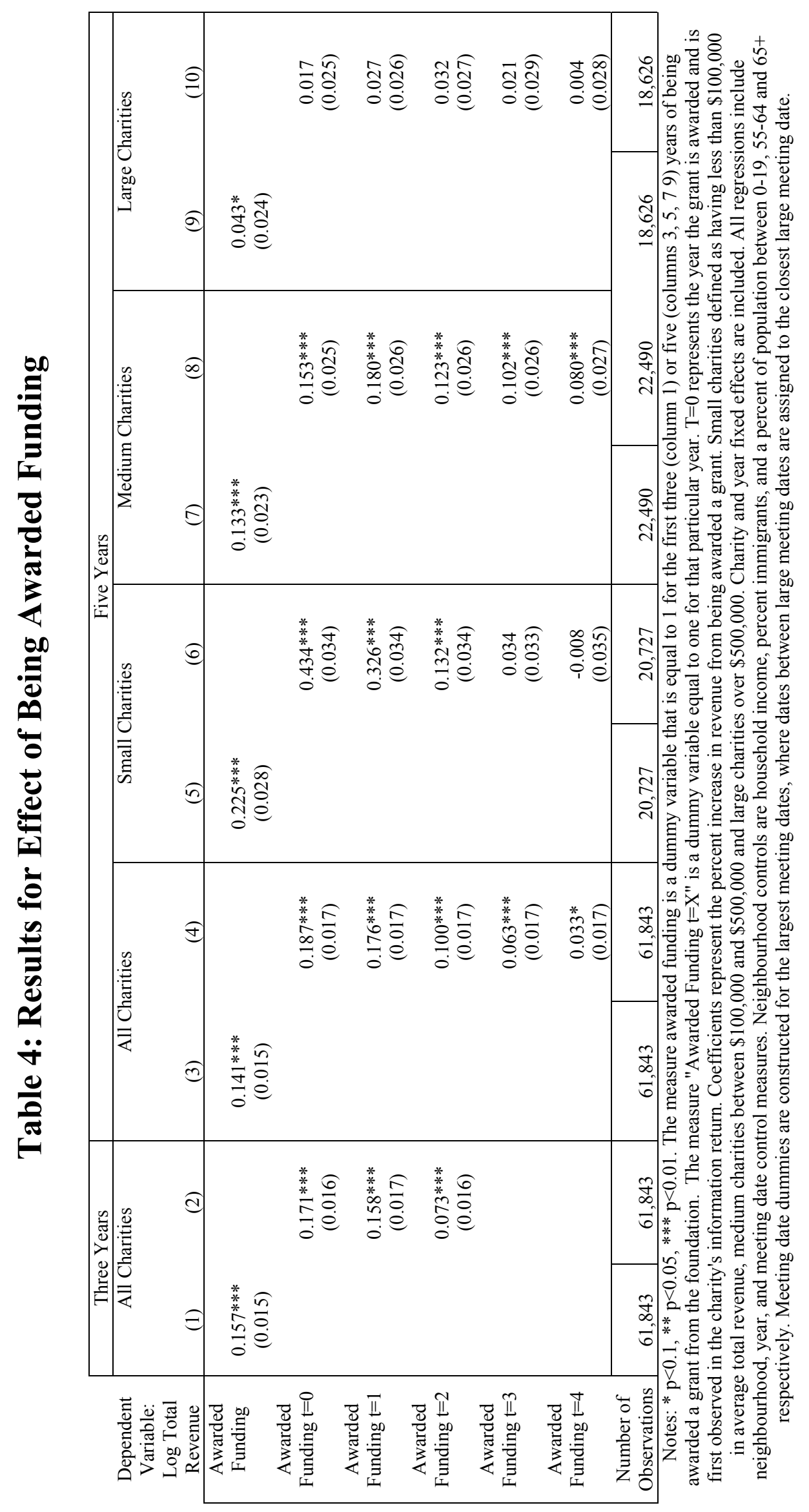




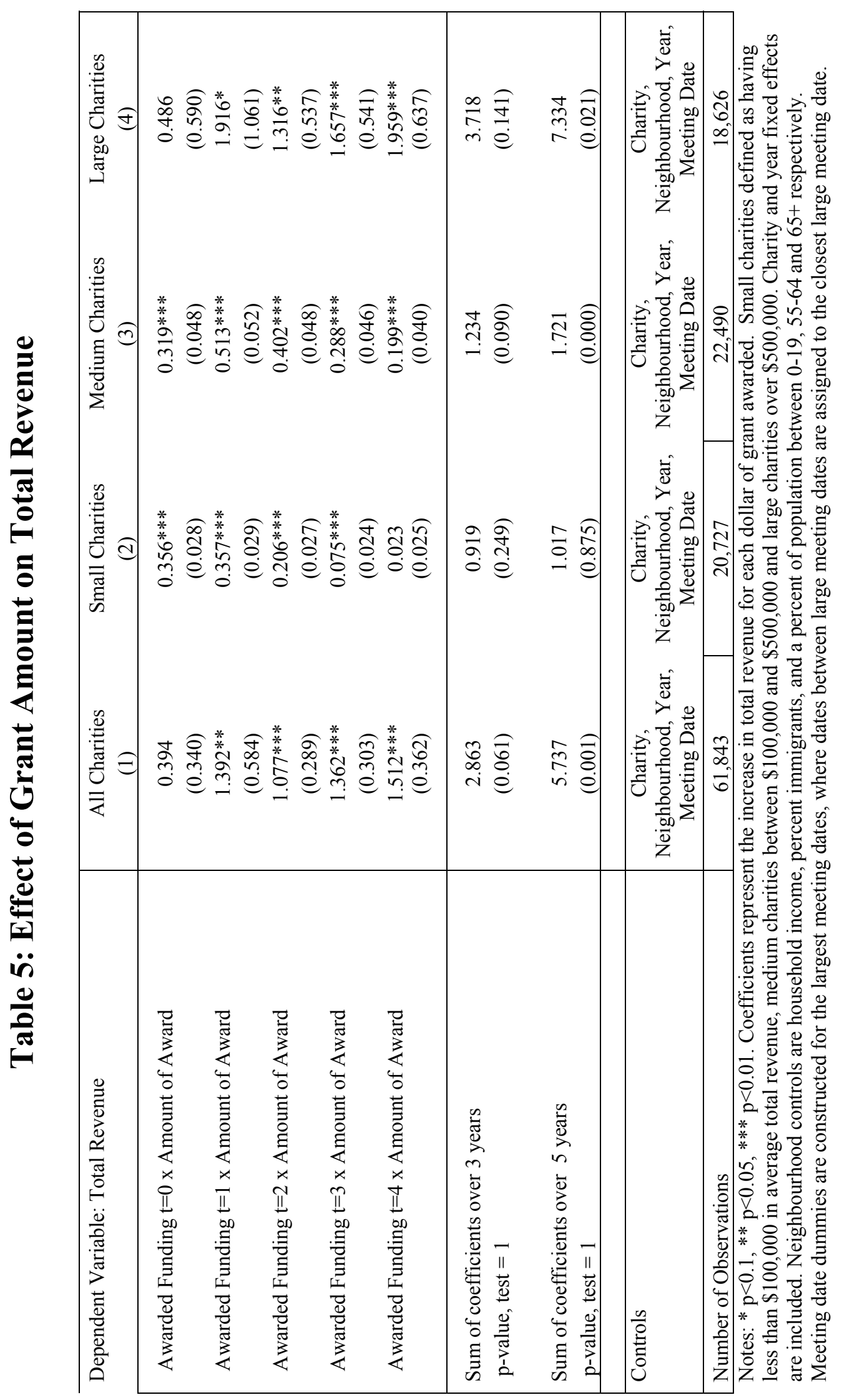



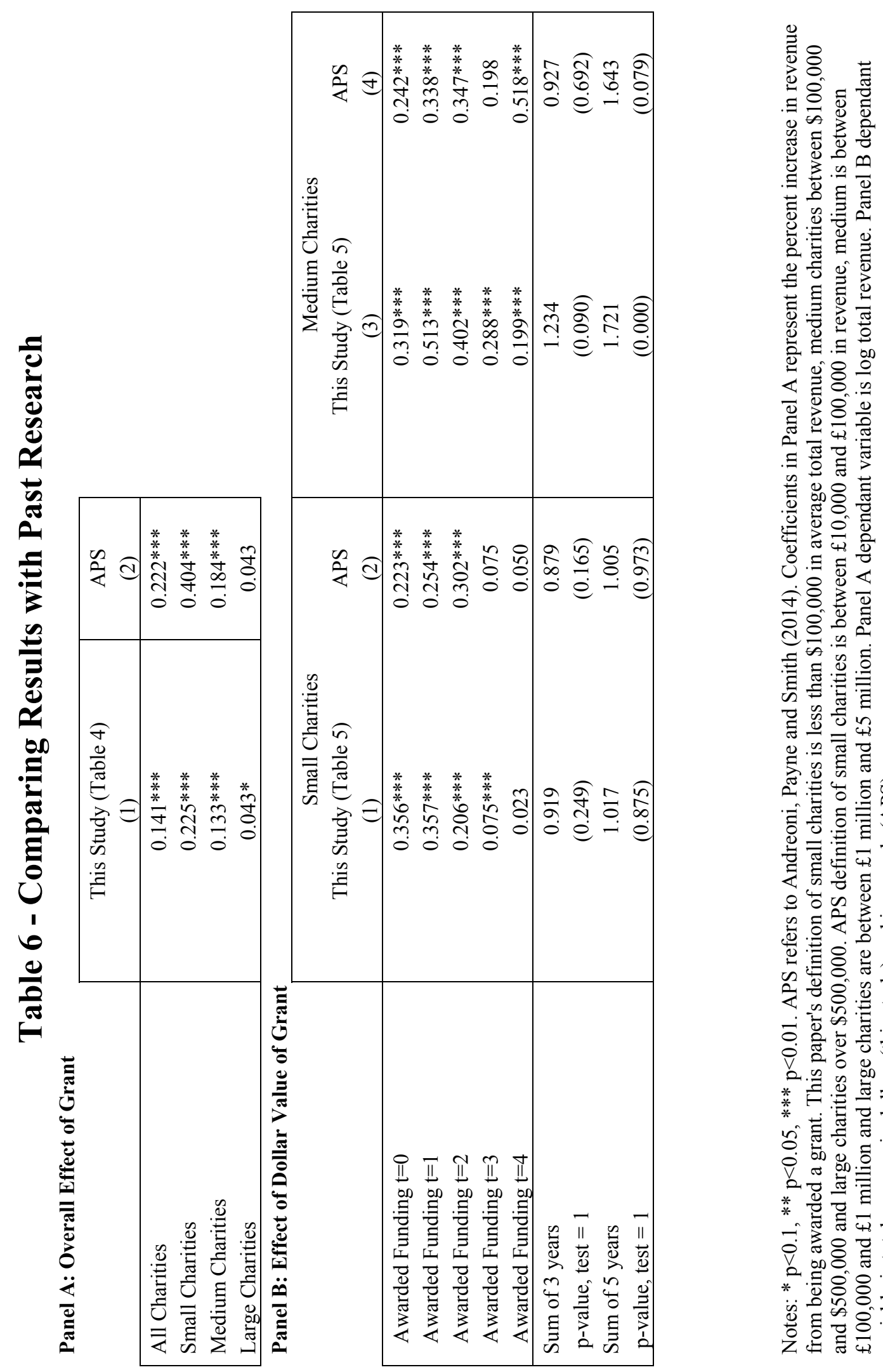

ㅇㅇㅇ

过完

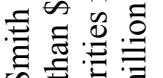

क 0 矛

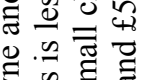

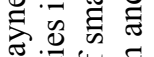

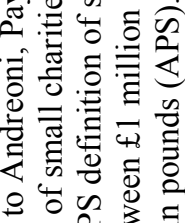

은

せ

น

○.

능 0

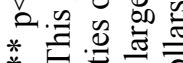

*

ค芫豞志

해

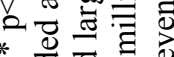

* 矛苛元

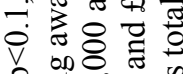

a

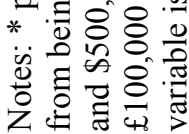




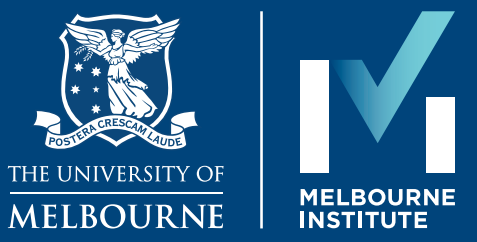

